\title{
Bilayered Oxide Scales Formed on Nickel
}

\author{
By Tokihiro Ueno*
}

\begin{abstract}
Bilayered scale of $\mathrm{NiO}$ is formed on not only impure but high-purity nickel by heating in air at temperatures of 900 to $1200^{\circ} \mathrm{C}$ for times up to $72 \mathrm{hr}$. It is found that scales consist of two layers which are metallographically and/or crystallographically different from each other. They can be classified into several types according to their metallographic and crystallographic structures.
\end{abstract}

(Received September 18, 1972)

\section{Introduction}

According to Wagner's theory ${ }^{(1)(2)}$ it is assumed that a volume diffusion of the reacting ions via corresponding point defects or a transport of electrons across the growing scale is a rate-determining process of the high-temperature oxidation of many metals. In the early work of Wagner and Grünwald ${ }^{(3)}$ on the oxidation of nickel it was stated that the observed oxidation rate could be elucidated on the basis of diffusion of nickel ions via cation vacancies through a uniform layer of NiO. This consideration was further confirmed by electrical studies on $\mathrm{NiO}^{(4) \sim(7)}$, and kinetic studies on the oxidation of nickel ${ }^{(8)(9)}$ and on the diffusion of radioactive nickel in $\mathrm{NiO}^{(10)(11)}$. Preece and Lucus ${ }^{(12)}$, on the other hand, showed that the oxide scale formed on nickel contained the single phase $\mathrm{NiO}$ and consisted of two layers which were different in morphology and in colour. They suggested that the diffusion of oxygen through the scale occurred to a considerable extent. Since then, many works have been done on the bilayered scale of $\mathrm{NiO}^{(13) \sim(18)}$, and it has been discussed on the basis of the inert marker studies whether the inward diffusion of oxygen occurs ${ }^{(13)} \sim(15)$. However, Gulbransen and Andrews ${ }^{(19)}$, and Terao ${ }^{(18)}$ have thrown doubt on the conclusions of the inert marker experiments.

Some investigators have pointed out that bilayered scales are formed on impure nickel, while monolayered scales on pure nickel ${ }^{(15) \sim(18)}$. In the present experiments it is shown that the bilayered scale is formed on not only impure but high-purity nickel and their structure is examined metallographically and crystal-

* Department of Applied Physics, Faculty of Engineering, Hokkaido University, Sapporo, Japan.

(1) C. Wagner: Z. Phys. Chem., B21 (1933), 25.

(2) C. Wagner: Atom Movements, Amer. Soc. Metals, Cleaveland, (1951), p. 153.

(3) C. Wagner and K. Grünwald: Z. Phys. Chem., B24 (1934), 455.

(4) H. H. Von Baumbach and C. Wagner: Z. Phys. Chem., B24 (1934), 59.

(5) C. A. Hogarth: Proc. Phys. Soc., B64 (1951), 691.

(6) F. J. Morin: Phys. Rev., 93 (1954), 1199.

(7) S. P. Mitoff: J. Chem. Phys., 35 (1961), 882.

(8) E. A. Gulbransen and K. F. Andrews: J. Electrochem. Soc., 101 (1954), 128.

(9) E. A. Gulbransen and K. F. Andrews: J. Electrochem. Soc., 104 (1957), 451.

Trans. JIM lographically.

\section{Experimental Procedure}

Nickel specimens used will be denoted as $\mathrm{N}_{1}, \mathrm{~N}_{2}$ and $N_{3}$ according to their purity. Impurity elements in these specimens are listed in Table 1. Type $\mathrm{N}_{3}$ nickel, the purest one, was supplied by Johnson, Matthey and Co., Limited. Starting materials composed of a set of crystallites nearly randomly oriented were cut into coupons about $0.5 \mathrm{~mm}$ thick. The nickel specimens were abraded mechanically or electrolytically in order to examine the effects of surface treatments on the growth of oxide scale. The mechanical polishing was carried out using Marumoto Nos. 100 and 300 and Linde " $B$ " alumina abrasive successively or carborundum powder of No. 1000 . The surfaces polished by the former procedure were smooth like a mirror, while those by the latter procedure were rough and far from the state of a mirror. After mechanical abrading the surfaces were polished electrolytically in $60 \%$ sulphulic acid at about $30^{\circ} \mathrm{C}$ using a current density of $0.5 \mathrm{~A} / \mathrm{cm}^{2}$ and $5 \mathrm{~V}$. The abraded or polished specimens were annealed in a $10^{-5}$ Torr vacuum at $550^{\circ} \mathrm{C}$ more than $5 \mathrm{hr}$ and degreased in benzene before and after annealing. A specimen was suspended by a Pt hook at the center of an electric furnace. The oxidation was carried out in air at temperatures of 900 to $1200^{\circ} \mathrm{C}$ for a varying time up to $72 \mathrm{hr}$, and then the specimen was removed from the furnace gradually over a period of $10 \mathrm{~min}$ and examined at room temperature.

With a microscope the gas/oxide and oxide/metal interfaces and cross-sections of the scale were exam-

(10) M. T. Shim and W. J. Moore: J. Chem. Phys., 26 (1957), 802.

(11) R. Linder and A. Akerström: Discussions Faraday Soc., 23 (1957), 133.

(12) A. Preece and G. Lucus: J. Inst. Metals, 81 (1952), 219.

(13) B. Ilshner and H. Pfeiffer: Naturwiss., 23 (1953), 603.

(14) J. A. Sartel and C. H. Li: J. Inst. Metals, 90 (1961), 92.

(15) B. M. Vasyutinsky and G. N. Kartmazov: Fiz. metal metalloved, 15 (1963), 132.

(16) G. C. Wood and I. G. Wright: Corrosion Science, 5 (1965), 841 .

(17) V. I. Arkharov, S. I. Ivanovskaya and A. S. Krivonosora: Fiz. metal metalloved, 22 (1966), 884.

(18) N. Terao: Japan. J. Appl. Phys., 10 (1971), 1256.

(19) E. A. Gulbransen and K. F. Andrews: J. Electrochem. Soc., 105 (1958), 363.

1973 Vol. 14 
Table 1 Impurity elements contained in the nickel specimens.

\begin{tabular}{c|c|c|c}
\hline Type of nickel & impure & \multicolumn{2}{|c}{ high-purity } \\
\cline { 3 - 4 } Impurity elements & $\mathrm{N}_{1}(\%)$ & $\mathrm{N}_{2}(\%)$ & $\mathrm{N}_{3}$ (ppm) \\
\hline $\mathrm{C}$ & 0.047 & 0.02 & \\
$\mathrm{Si}$ & 0.09 & 0.005 & 4 \\
$\mathrm{Mn}$ & 0.29 & 0.002 & \\
$\mathrm{~S}$ & 0.03 & 0.001 & \\
$\mathrm{Cr}$ & 0.01 & 0.005 & 1 \\
$\mathrm{Cu}$ & 0.03 & 0.005 & 7 \\
$\mathrm{Ag}$ & $0.8 \sim 0.9$ & 0.03 & 1 \\
$\mathrm{Fe}$ & & & 1 \\
$\mathrm{Co}$ & & 0.001 & \\
$\mathrm{Al}$ & & \\
$\mathrm{Ag}$ & & \\
$\mathrm{Pb}$ & &
\end{tabular}

ined. The oxide/metal interface was observed after dissolving away the base nickel with an electrochemical technique ${ }^{(20)}$. There were no suitable etching reagents for polished oxide sections. Scales freed from the metal were fractured for examination of their cross-sections ${ }^{(14)}$. The fractured surfaces were not so flat as the polished ones; they were difficult to lie within the focal plane of microscope objective.

The X-ray diffraction method was used in studying crystal orientation of the layer of more than one micron in thickness. X-rays were irradiated on the gas/oxide interface of the scale attached to the metal to examine the outer layer and also on the oxide/ metal interface of the scale freed from the metal to examine the inner layer. The $\mathrm{X}$-ray radiation used was $\mathrm{CuK} \alpha$ or $\operatorname{MoK} \alpha$.

\section{Results}

\section{Oxide scales formed on impure nickel}

Photograph 1 shows a fractured cross-section of the scale formed on a type $\mathrm{N}_{1}$ nickel specimen by heating at $1170^{\circ} \mathrm{C}$ for $29 \mathrm{hr}$. Under polarized light two layers of different colours, a black outer layer and a palegreen inner layer, were distinctly observed. Furthermore, the inner layer can be divided into two layers of different tints of pale green. Using bright field

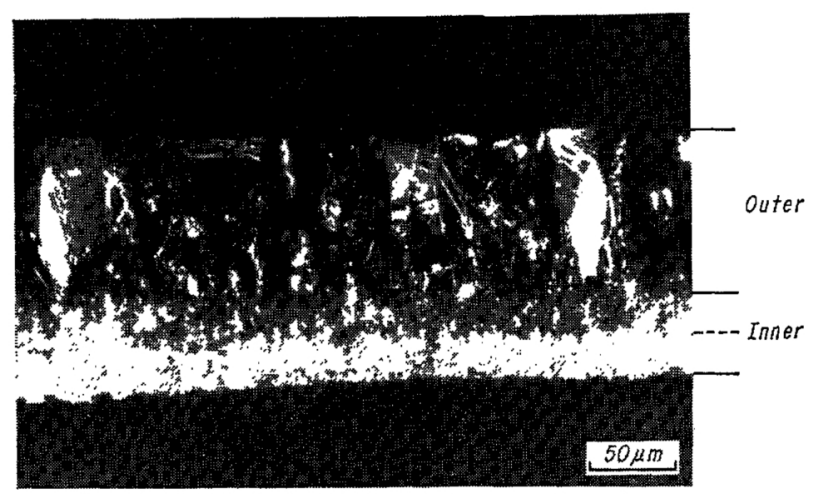

Photo. 1 Fractured cross-section of an oxide scale formed on impure nickel after $29 \mathrm{hr}$ at $1170^{\circ} \mathrm{C}$ in air.

(20) U. R. Evans and J. Stockdales: J. Chem. Soc., 131 (1929), 2651. illumination it was found that the outer layer was composed of coarse and columnar grains, while the inner layer consisted of fine equiaxed grains. The thicknesses of the outer and inner layers were 95 and 50, and those of two sub-inner layers 30 and $20 \mu \mathrm{m}$, respectively. The average ratio of thicknesses of two layers is 13: 7 and that of sub-inner layers $4: 3$. By $\mathrm{X}$-ray diffraction $(\mathrm{CuK} \alpha$ source) the oxide of the outer and inner layers was identified as $\mathrm{NiO}$.

Photomicrographs were taken of the outer surfaces of the above-mentioned specimens without polishing, etching, or otherwise altering the existing surface. As reproduced in Photo. 2, the specimen shows welldefined oxide grains; a large number of flat faces predominate and are located at the same height above the base nickel. By X-ray diffraction the crystal orientation of the black outer layer was examined (MoK $\alpha$ source). The diffraction patterns of the outer layer of seventeen specimens revealed the existence of two types of crystal orientation. One of them is shown in Photo. 3(a). The outer layer of the scale is composed of a set of crystallites with their $\{100\}$ planes preferentially parallel to the surface. The other is shown in Photo. 3(b). The outer layer of the scale is composed of a set of crystallites with their $\{311\}$ planes parallel to the surface. For simplicity, the oxide scale having the outer layer of the former type will be denoted as " $R_{1}$ " and that of the latter type as " $T_{1}$ ". The frequent occurrence of the type $R_{1}$ and $T_{1}$ scale was in the ratio of 10:7. The origin of such different types of crystal orientation will remain as a subject of further study.

Photograph 4(a) shows the oxide/metal interface of the type $R_{1}$ scale. The inner layer is composed of grains considerably finer than those of the outer layer. By X-kay diffraction due to these grains $(\mathrm{CuK} \alpha$ source), ring patterns were observed as shown in Photo. 4(b). This shows that the crystallites of the inner layer of the type $R_{1}$ scale is nearly randomly oriented.

The thicknesses of the black outer layer and palegreen inner layers increased with oxidation time. There was no appreciable difference between the type $R_{1}$ and $T_{1}$ scales in the oxidation rate of the respective layers and the interface topography. Within the first few minutes of oxidation the outer layer of the type

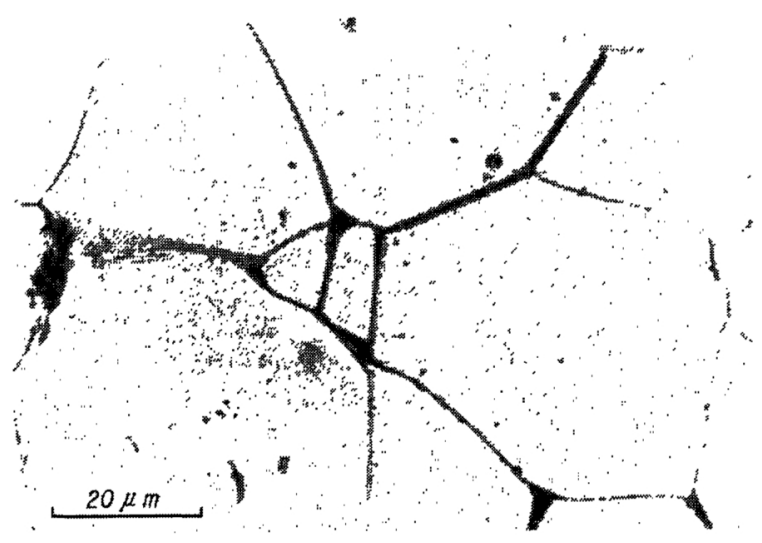

Photo. 2 Surface of the oxide scale in Photo. 1. 

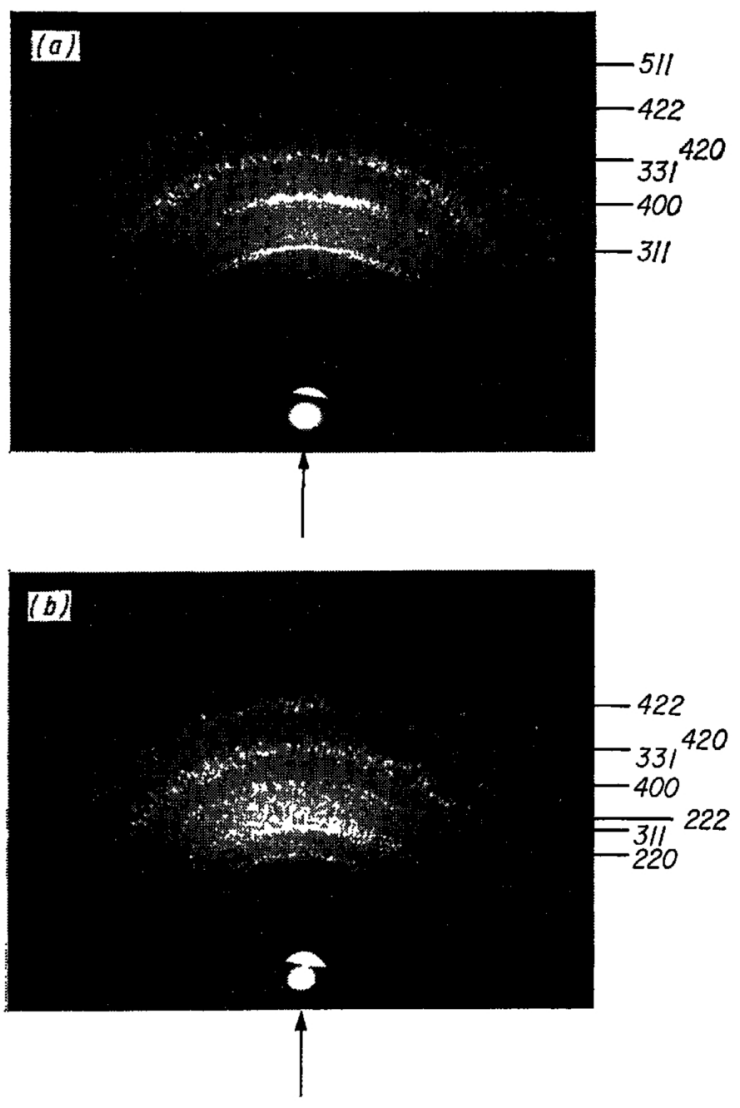

Photo. 3 X-ray diffraction patterns of the outer layer of the scale formed on impure nickel (MoK $\alpha$ source); (a) the type $R_{1}$ scale with glancing angle of $19.9^{\circ}$ and (b) the type $T_{1}$ scale with glancing angle of $16.4^{\circ}$. The arrows indicate the normal direction to the surface of the specimen.
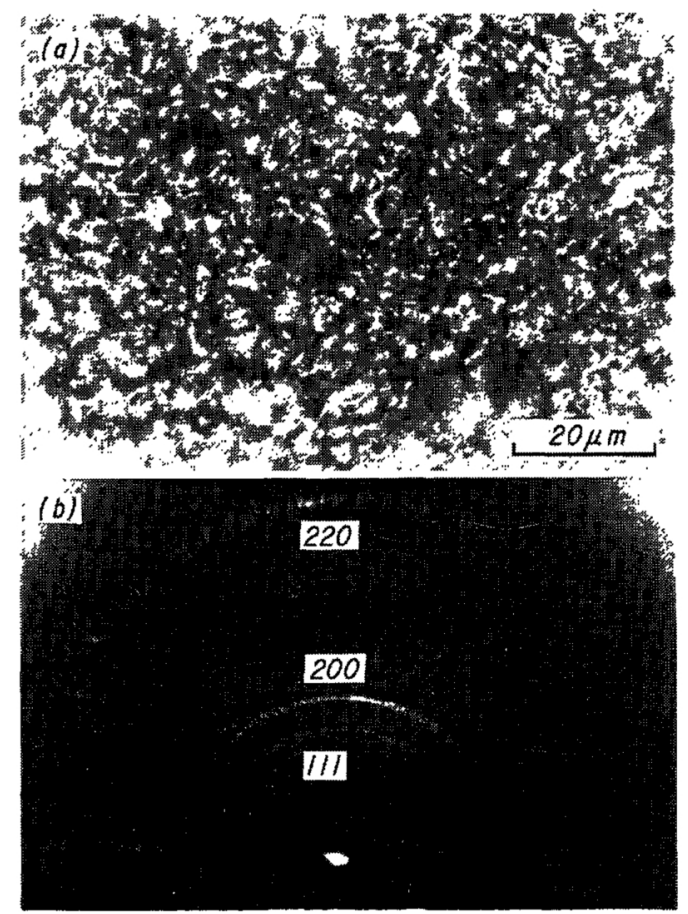

Photo. 4 (a) Oxide/metal interface and (b) X-ray diffraction pattern of the inner layer of the scale in Photo. 1 (CuK $\alpha$ source).
$R_{1}$ scale turned from a random to a preferred orientation, while the inner layer showed no orientation of crystal orientation for periods up to $50 \mathrm{hr}$. In the initial stage of oxidation the outer layer of the type $\mathrm{T}_{1}$ scale had a set of crystallites with their $\{111\}$ planes parallel to the surface. As the scale was thickened, it turned gradually to the preferred orientation showing that the $\{311\}$ planes were parallel to the surface. After $50 \mathrm{hr}$, however, the $\{311\}$ planes were parallel to the surface throughout the entire thickness of the outer layer. The change in colour and the indication of crystal orientation occurred quite abruptly at the interface between the two layers. Such characters of the scale were established at any temperature between 900 and $1200^{\circ} \mathrm{C}$.

\section{Oxide scales formed on high-purity nickel}

After oxidation for $45 \mathrm{hr}$ at $1170^{\circ} \mathrm{C}$, a bilayer, a black outer and a green inner layer, was formed on a specimen of type $\mathrm{N}_{3}$ nickel, as shown in Photo. 5(a). The outer layer is composed of coarse and columnar grains, while the inner layer of fine equiaxed grains. Their thicknesses were 87 and $10 \mu \mathrm{m}$, respectively, and the ratio of the thicknesses of two layers was $8.7: 1$. This type of bilayered scale will be denoted as " $R_{2}$ ". Photograph 5(b) shows another type of the bilayered scale formed on type $\mathrm{N}_{3}$ nickel by heating for $50 \mathrm{hr}$ at $1170^{\circ} \mathrm{C}$. Both the outer and inner layers are black and composed of coarse grains. Their thicknesses were 52 and $30 \mu \mathrm{m}$, respectively, and the thickness ratio between the two layers was $1.8: 1$. This type of bilayered scale will be denoted as " $T_{2}$ ". The boundary
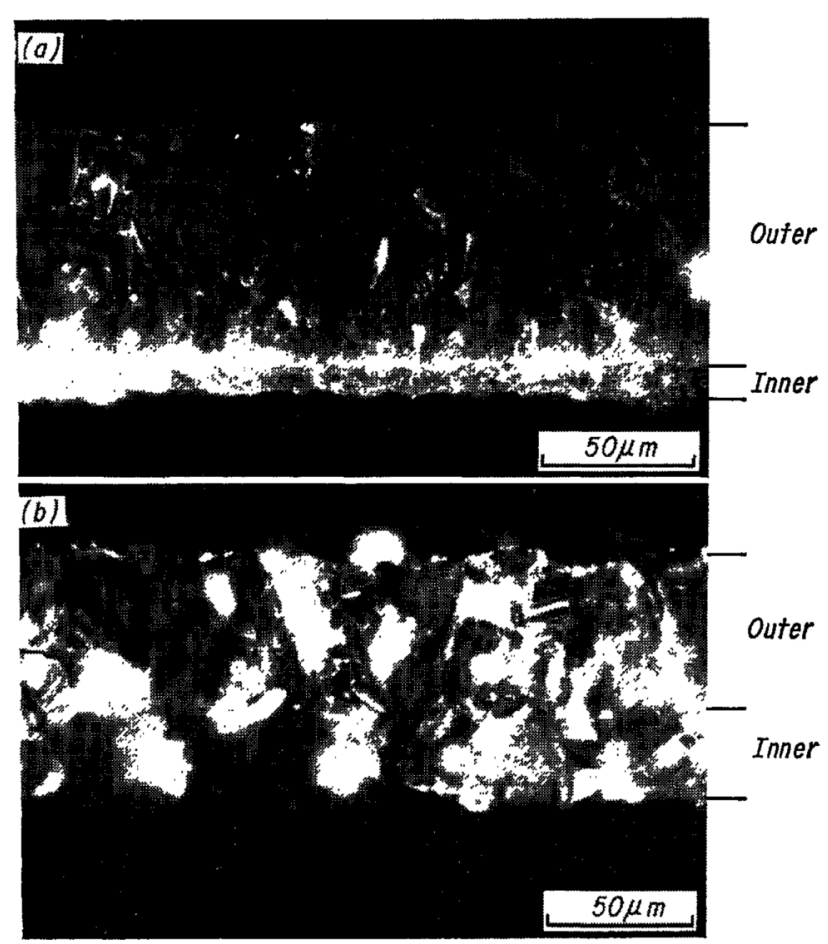

Photo. 5 Fractured cross-sections of two types of bilayered scale formed on high-purity nickel (type $\mathrm{N}_{3}$ ); (a) the type $\mathrm{R}_{2}$ scale composed of a black outer layer and a green inner layer, and (b) the type $T_{2}$ scale composed of two black layers. 
of the interface between these layers was not so distinct as other types of scale. In the present work the surfaces abraded with carborundum powder of No. 1000 always led to the formation of the type $R_{2}$ scale. When a specimen was electrolytically polished after abrasion, the type $T_{2}$ scale was formed frequently with increasing time of polishing. However, if the surfaces were abraded with fine alumina abrasive, then type $T_{2}$ scale always formed on the surface irrespective of whether electrolytically polished or not. By X-ray diffraction ( $\mathrm{CuK} \alpha$ source) the oxide of the type $R_{2}$ and $T_{2}$ scale was identified as $\mathrm{NiO}$.

The outer surface of the type $R_{2}$ and $T_{2}$ scale showed typical growth facets; rectangular grains parallel to the surface (Photo. 6(a)) and triangular grains inclined or parallel to the surface (Photo. 6(b)). Obwerved growth facets were not so flat as the type $R_{1}$ and $T_{1}$ scales. The X-ray diffraction patterns ( $M \circ K \alpha$ source) revealed that the outer layer of the type $R_{2}$ scale was composed of a set of crystallites with their $\{100\}$ planes preferrentially parallel to the surface, while that of the type $T_{2}$ scale with their $\{311\}$ planes parallel to the surface.

Photomicrographs of the oxide/metal interface of the type $R_{2}$ and $T_{2}$ scale are reproduced in Photos. 7(a) and (b), respectively. The inner layer of the type $R_{2}$ scale is composed of finer grains than the type $T_{2}$ scale. Examination by $\mathrm{X}$-ray diffraction ( $\mathrm{CuK} \alpha$ source) shows that the crystallites of the inner layer of the type $R_{2}$ scale are nearly randomly oriented and those of the type $T_{2}$ scale exhibit slightly a tendency to have their $\{111\}$ planes parallel to the surface (Photo. 8(b)).

In the temperature range from 900 to $1200^{\circ} \mathrm{C}$ the type $R_{2}$ scale of the bilayered structure was established

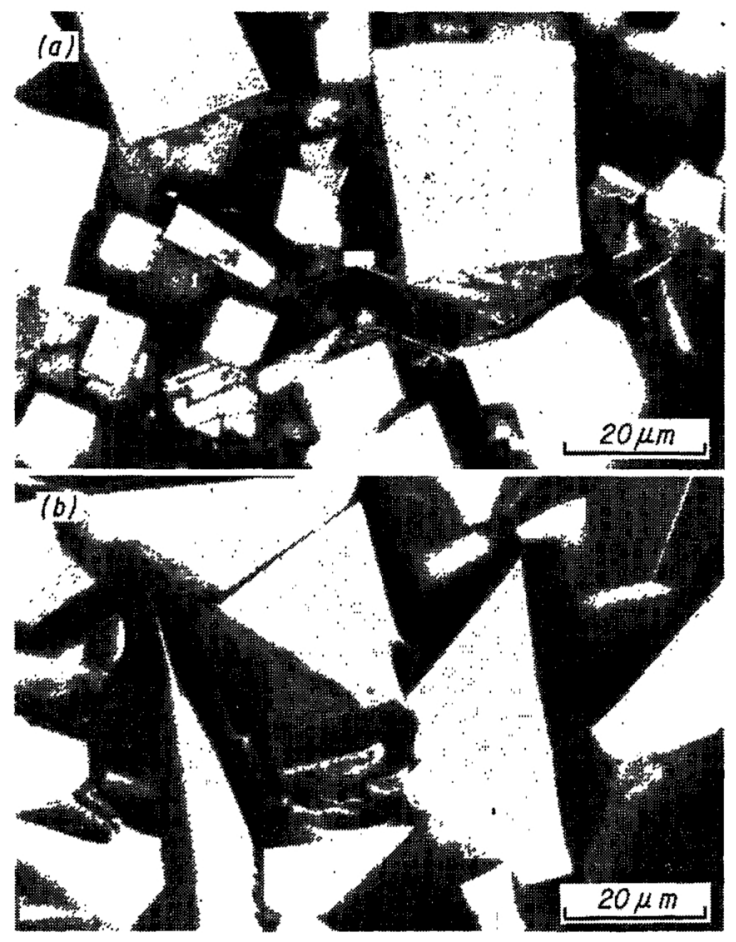

Photo. 6 Growth facets of the outer surfaces of the type (a) $R_{2}$ and (b) $T_{2}$ scales. during the intial stage of oxidation and its two layers were thickened with time. As to the type $T_{2}$ scale, within the same temperature range the layer consisting of crystallites with their $\{111\}$ planes parallel to the surface was formed on metal in the first place and subsequently another with their $\{311\}$ planes parallel to the surface grew on the scale already formed. This change in crystal orientation from the former to the latter takes place rather gradually at the gas/oxide interface and remains unchanged during the course

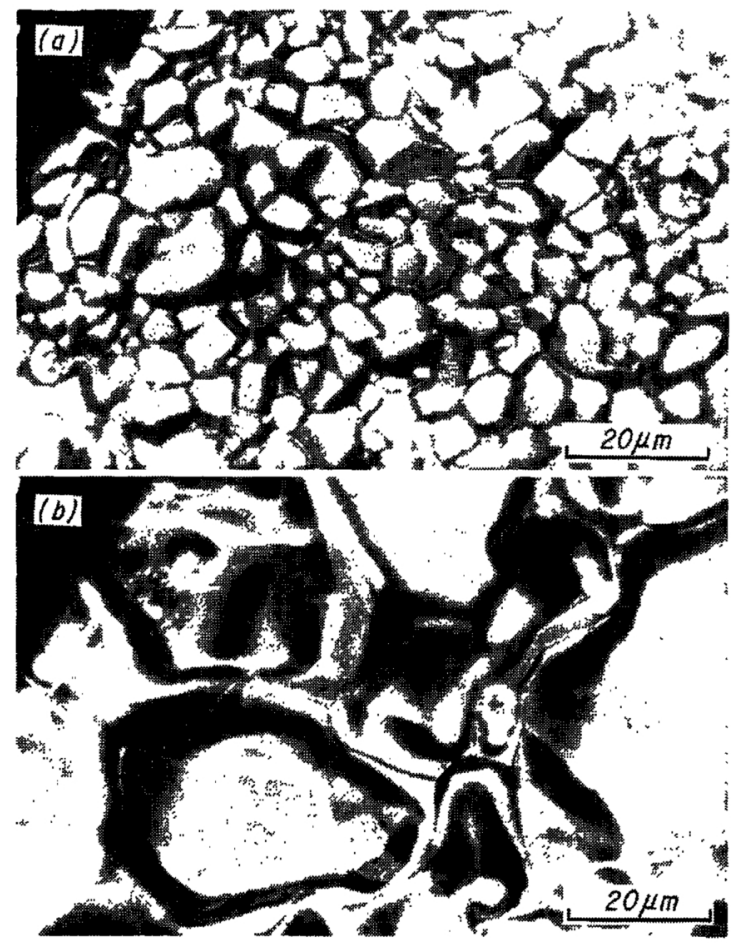

Photo. 7 Oxide/metal interfaces of the type (a) $R_{2}$ and (b) $T_{2}$ scales.

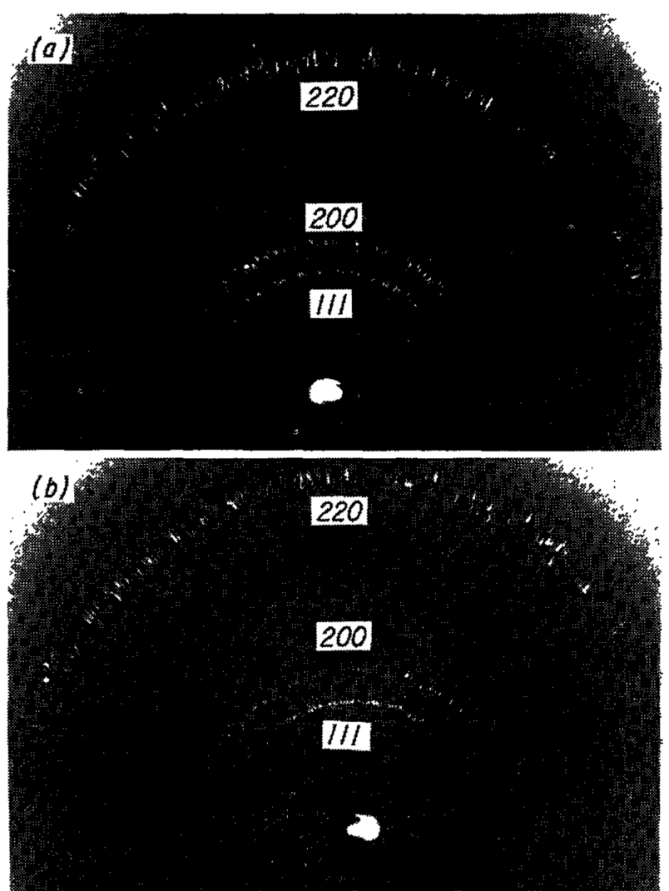

Photo. 8 X-ray diffraction patterns of the inner layers of the type (a) $R_{2}$ and (b) $T_{2}$ scales. ( $\mathrm{CuK} \alpha$ source). 


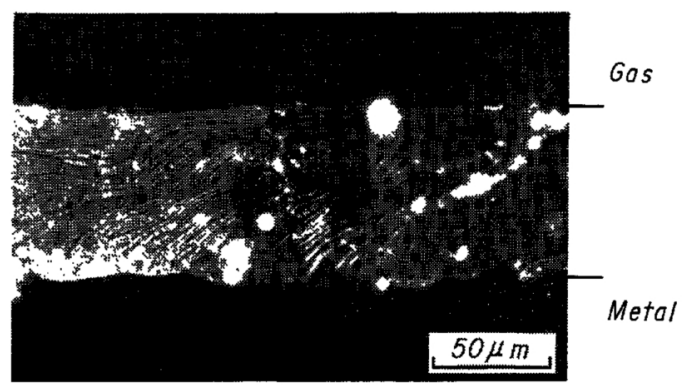

Photo. 9 Fractured cross-section of a monolayered oxide scale.

of oxidation.

Sometimes a black monolayer was formed on the mirror-like surfaces. This layer is similar to the outer layer of the type $T_{1}$ scale. In the first stage the $\{111\}$ planes are parallel to the surface. As the scale is thickened, however, the $\{311\}$ planes are parallel to the surface throughout the entire thickness. Photograph 9 shows the cross-section of the monolayered scale formed on type $\mathrm{N}_{2}$ nickel by heating for $72 \mathrm{hr}$ at $1170^{\circ} \mathrm{C}$ after abrading with fine alumina abrasive.

Any appreciable difference between the scales formed on type $\mathrm{N}_{2}$ and $\mathrm{N}_{3}$ nickel was not found in the present work.

\section{Discussion}

Whether the type $R_{2}$ scale or the type $T_{2}$ scale is formed depends on the surface treatments. It can be said that these two types are different in colour, crystal orientation and morphology at the cross-section as well as morphology at the gas/oxide and oxide/ metal interfaces. Oshida and Nakayama reported that the wet-oxidized films formed on mechanically polished stainless-steel were different from those on stainless-steels polished chemically ${ }^{(21)}$. However, the present work has not given sufficient information to clarify the dependence of the bilayered structure on specimen history.

The oxidation of metal is intimately related to the substrate orientation ${ }^{(22)}$. Mach has been reported about the epitaxy of $\mathrm{NiO}$ films on nickel specimens of thin films ${ }^{(23)(24)}$, oriented crystals ${ }^{(25)}$ and spherical single crystals ${ }^{(22)(26)}$ : Definite relations are seen between crystal orientations of $\mathrm{NiO}$ and substrate nickel. Besides, it has been suggested that the oxidation rate of nickel depends on crystal orientation of nickel or $\mathrm{NiO}^{(22)}$. In the present work the first layer to appear on a polycrystalline metal surface not

(21) Y. Oshida and T. Nakayama: J. Japan Inst. Metals, 35 (1971), 1108.

(22) A. T. Gwathmey and K. R. Lawless: The Surface Chemistry of Metals and Semiconductors, ed. by H. C. Gatos, John Wiley \& Sons, New York, (1960), p. 483.

(23) H. Schmid: Cobalt, 6 (1960), 8.

(24) A. E. Berkowitz and J. H. Greiner: J. Appl. Phys., 36 (1965), 3330.

(25) J. B. Newkirk and W. G. Martin: Trans. Met. Soc. AIME, 212 (1958), 398

(26) M. Otter: Z. Naturforsch., 14a (1959), 355. preferentially oriented is also randomly oriented, though, owing to the variation in the rate of growth with orientation, the oxide grains of particular orientation would predominate. Such a tendency of crystal orientation is apparently seen in the growth of the outer layer of the type $R_{1}$ and $R_{2}$ scales, while their inner layers have no trend of crystal orientation. From the view point of crystal orientation, it is difficult to explain the formation of these bilayered scales in terms of an outward diffusion of metal ions. The $\{111\}$ planes of crystallites in the inner layers of the type $T_{1}$ and $T_{2}$ scale are independent of the substrate orientation and one of the closest-packed surfaces of the $\mathrm{NiO}$ crystals. The fact that the gradual change of crystal orientation at the gas/oxide interface is memorized at the depth of the scale suggests that these layers grow at the gas/oxide interface.

It is a well-known fact that $\mathrm{NiO}$ closely stoichiometric appears green or pale-green, whereas material that has an excess of oxygen or, in other words, metal ion vacancies trend more toward a black appearance $^{(27) \sim(31)}$. As one of the possible mechanism for this fact, Newman and Chrenko mentioned charge transfer spectrum involving $\mathrm{Ni}^{3+}$ ions introduced by $\mathrm{Ni}^{2+}$ vacancies ${ }^{(31)}$. Prased and Tendulkar made a chemical analysis on $\mathrm{NiO}$ obtained by heating nitrate in $\operatorname{air}^{(27)}$. The content of excess oxygen occluded in black $\mathrm{NiO}$ was estimated at 0.85 weight per cent. Wright and Andrews did electrical measurements on $\mathrm{NiO}$ strips ${ }^{(32)}$. It was estimated at 0.62 atomic per cent. Probably black NiO contains a considerable amount of excess oxygen. Accordingly, it is difficult to detect the concentration gradient of vacancies in the black layer from its colour change. If the green and pale-green layers are also formed by a diffusion mechanism, it is difficult for them to give the defect type and concentration gradient from its colour. It is sure, however, that the concentration gradient of the defect changes discontinuously at the interface between the outer and inner layers in the type $R_{1}, T_{1}$ and $\mathrm{R}_{2}$ scales.

\section{Summary}

(1) Observed bilayered structures formed on nickel are summarized in Table 2.

(2) According to the colour and crystal orientation it is difficult to explain the formation of green and pale-green layers of $\mathrm{NiO}$ in terms of an outward diffusion of metal ions, while that of the black layers

(27) M. LeBlanc and H. Sachse: Z. Electrochem., 32 (1962), 58.

(28) M. Prasad and M. G. Tendulkar: J. Chem. Soc., 133 (1931), 1403.

(29) F. A. Kröger, H. J. Vink and J. Van den Boomgaard: Physica, 18 (1952), 77.

(30) F.J.Morin: Semiconductors, ed. by N.B. Hanay, Reinhold, New York, (1959), p. 622.

(31) R. Newman and R. M. Chrenko: Phys. Rev., 114 (1959), 1507.

(32) R. W. Wright and J. P. Andrews: Proc. Phys. Soc., A62 (1949), 446. 
Table 2 Bilayered structures of scales formed on nickel.

\begin{tabular}{|c|c|c|c|c|c|c|c|}
\hline \multicolumn{2}{|c|}{ Type of nickel } & \multicolumn{2}{|r|}{$\mathrm{N}_{1}$} & \multicolumn{2}{|r|}{$\mathrm{N}_{2}$} & \multicolumn{2}{|r|}{$\mathrm{N}_{3}$} \\
\hline Polishing & Scale & Colour & $\begin{array}{l}\text { Planes parallel } \\
\text { to the surface }\end{array}$ & Colour & $\begin{array}{l}\text { Planes parallel } \\
\text { to the surface }\end{array}$ & Colour & $\begin{array}{l}\text { Planes parallel } \\
\text { to the surface }\end{array}$ \\
\hline $\begin{array}{l}\text { Mechanically } \\
\text { (with SiC) }\end{array}$ & $\begin{array}{l}\text { Outer } \\
\text { Inner }\end{array}$ & $\begin{array}{c}\text { Black } \\
\text { Pale-Green }\end{array}$ & $\begin{array}{c}\{100\} \text { or }\{311\} \\
\text { Random }\end{array}$ & $\begin{array}{l}\text { Black } \\
\text { Green }\end{array}$ & $\begin{array}{c}\{100\} \\
\text { Random }\end{array}$ & $\begin{array}{l}\text { Black } \\
\text { Green }\end{array}$ & $\begin{array}{c}\{100\} \\
\text { Random }\end{array}$ \\
\hline Electrolytically & $\begin{array}{l}\text { Outer } \\
\text { Inner }\end{array}$ & $\begin{array}{c}\text { Black } \\
\text { Pale-Green }\end{array}$ & $\begin{array}{c}\{100\} \text { or }\{311\} \\
\text { Random }\end{array}$ & $\begin{array}{l}\text { Black } \\
\text { Black }\end{array}$ & $\begin{array}{l}* \quad\{311\} \\
\quad\{111\}\end{array}$ & $\begin{array}{l}\text { Black } \\
\text { Black }\end{array}$ & $\begin{array}{ll}* & \{311\} \\
& \{111\}\end{array}$ \\
\hline $\begin{array}{l}\text { Mechanically } \\
\text { (with } \mathrm{Al}_{2} \mathrm{O}_{3} \text { ) }\end{array}$ & $\begin{array}{l}\text { Outer } \\
\text { Inner }\end{array}$ & $\begin{array}{c}\text { Black } \\
\text { Pale-Green }\end{array}$ & $\begin{array}{c}\{100\} \text { or }\{311\} \\
\text { Random }\end{array}$ & $\begin{array}{l}\text { Black } \\
\text { Black }\end{array}$ & $\begin{array}{ll}* & \{311\} \\
& \{111\} \\
\end{array}$ & $\begin{array}{l}\text { Black } \\
\text { Black }\end{array}$ & $\begin{array}{l}* \quad\{311\} \\
\quad\{111\} \\
\end{array}$ \\
\hline Electrolytically & $\begin{array}{l}\text { Outer } \\
\text { Inner }\end{array}$ & $\begin{array}{c}\text { Black } \\
\text { Pale-Green }\end{array}$ & $\begin{array}{c}\{100\} \text { or }\{311\} \\
\text { Random }\end{array}$ & $\begin{array}{l}\text { Black } \\
\text { Black }\end{array}$ & $\begin{array}{l}* \quad\{311\} \\
\end{array}$ & $\begin{array}{l}\text { Black } \\
\text { Black }\end{array}$ & $\begin{array}{ll}* & \{311\} \\
& \{111\}\end{array}$ \\
\hline
\end{tabular}

*Sometimes a black monolayer is formed on the mirror-like surfaces polished mechanically with fine alumina abrasive or polished electrolytically after abrasion.

of $\mathrm{NiO}$ is considered to be due to the outward diffusion of $\mathrm{Ni}^{2+}$ ions via cation vavancies.

\section{Acknowlegments}

Thanks are due to Prof. Y. Shimomura of Uni- versity of Osaka Prefecture for his useful discussions, Prof. A. Odajima for his kindness through the work, Prof. N. Sato for his advice and Dr. M. Kitamura for his critical review of the manuscript. 